\title{
RP-HPLC METHOD DEVELOPMENT AND VALIDATION OF TRAMADOL HYDROCHLORIDE IN BULK FORM BY ION-PAIR LIQUID CHROMATOGRAPHY
}

\author{
Sinha Manish*, Verma Vivek \\ Amar Shaheed Baba Ajit Singh Jujhar Singh Memorial College of Pharmacy, Bela (Ropar) Punjab, India \\ *Corresponding author's email: manish.pharm2000@gmail.com
}

\begin{abstract}
:
A simple, selective, accurate and precise high-performance liquid chromatographic (HPLC) method for estimation of Tramadol $\mathrm{HCl}$ in bulk form was developed \& validated. The estimation was carried out on Phenomenax luna C-18 (250x4.6 $\mathrm{mm}, 5 \mu$ ) column using a mobile phase consisting of $20 \mathrm{mM}$ potassium dihydrogen phosphate, 1.75mM 1-octane sulfonic acid sodium salt, $2 \%$ isopropanol: Methanol $(25: 75 \mathrm{v} / \mathrm{v})$ of $\mathrm{pH} 4.0$ adjusted with orthophosphoric acid, at a flow rate $1 \mathrm{ml} / \mathrm{min}$. The UV detection was carried out at $272 \mathrm{~nm}$. Method validation was performed as per the ICH guidelines. The method was validated for the precision, accuracy, linearity and robustness.
\end{abstract}

Key words: RP-HPLC estimation, Validation and Tramadol.

\section{INTRODUCTION:}

IUPAC name of Tramadol Hydrochloride is (IRS,2RS)2-[(dimethylamino)methyl]- 1-(3 methoxyphenyl) cyclohexanol hydrochloride. Tramadol is a synthetic codeine analogue that is a weak $\mu$-opioid receptor agonist. It is used as an oral non-steroidal antiinflammatory drug with good analgesic and tolerability profile in various painful conditions. ${ }^{1}$ In literature survey several methods like spectrophotometry ${ }^{2-7}$, HPTLC $^{8-9}$ and HPLC ${ }^{10-14}$ are reported for estimation of Tramadol $\mathrm{HCl}$ either alone or with other drugs.

Tramadol $\mathrm{HCl}$ is an official drug in Indian Pharmacopoeia $2010^{15}$, British Pharmacopoeia $2009^{16}$ and United State Pharmacopoeia ${ }^{17}$. Most of the methods were on estimation of Tramadol $\mathrm{HCl}$ in biological samples. As per literature survey there is no method for the estimation of Tramadol $\mathrm{HCl}$ by ion pair liquid chromatography. The use of ion pair reagent in the estimation of Tramadol with comparatively more hydrophobic conditions enhanced the scope of the work in simultaneous estimation of Tramadol $\mathrm{HCl}$ with those drugs, which are more hydrophobic in nature. The developed method is fast, simple, precise and reliable method for routine analysis. The present RP-HPLC method was validated as per the ICH guidelines.

\section{MATERIAL AND METHODS:}

Reagents and Chemicals: HPLC grade Methanol, Triple distilled water, Potassium dihydrogen phosphate, 1-Octane sulfonic acid sodium salt and Isopropanol were used in the study.

Chromatographic conditions: Shimadzu prominence UFLC 2000 equipped with SPD-20A UV detector and Phenomenax Luna C18 $(250 \times 4.6 \mathrm{~mm}$ i.d $)$ column. The mobile phase consisting of $20 \mathrm{mM}$ potassium dihydrogen phosphate, $1.75 \mathrm{mM} 1$-octane sulfonic acid sodium salt, $2 \%$ isopropanol : Methanol $(25: 75 \mathrm{v} / \mathrm{v})$ of $\mathrm{pH} 4.0$ adjusted with orthophosphoric acid.

\section{Preparation of standard solution:}

Preparation of stock solution of TRA: Weigh accurately $10 \mathrm{mg}$ of TRA and transferred into $10 \mathrm{ml}$ volumetric flask add $5 \mathrm{ml}$ of methanol and sonicated for 10 min and diluted up to mark with methanol to get a stock solution having strength $1000 \mu \mathrm{g} / \mathrm{ml}$.

Preparation of working Standard solution of TRA: $100 \mu \mathrm{g} / \mathrm{ml}$ solution of TRA was prepared by diluting $1 \mathrm{ml}$ stock solution to $10 \mathrm{ml}$ with methanol and further diluted with methanol to get the concentration range of 10,20 , $30,40,50 \mu \mathrm{g} / \mathrm{ml}$ of TRA.

Method Validation: The developed method was validated for linearity and range, accuracy, precision, Limit of detection, Limit of quantitation and robustness as per ICH guidelines ${ }^{18}$.

\section{RESULT AND DISCUSSION:}

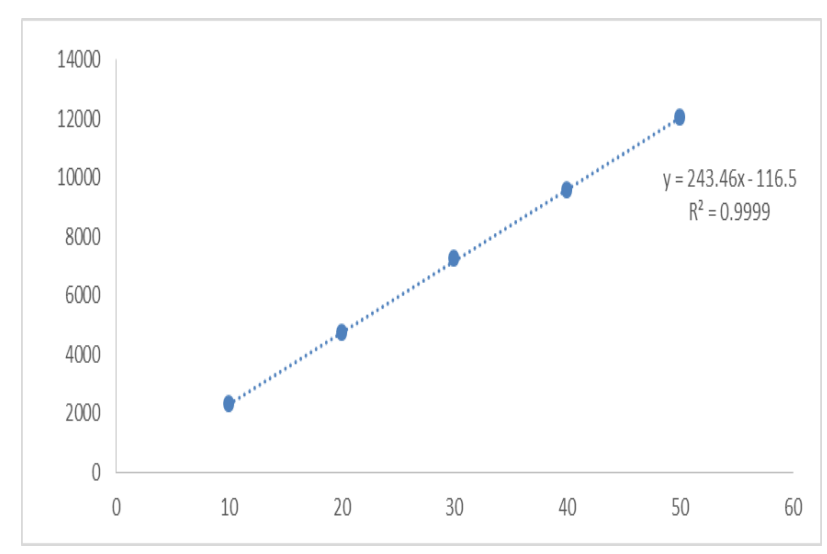

Figure 1: Calibration curve of Tramadol $\mathrm{HCl}$

Linearity: Linearity of the method was evaluated by constructing calibration curves at five concentration levels over a range of $10-50 \mu \mathrm{g} / \mathrm{ml}$. The calibration curve was linear and regression equation found to be $\mathrm{y}=$ 
$243.6 x-116.5$ with correlation coefficient $\left(r^{2}\right) 0.999$ as shown in fig. 1.

Inter-day and intra-day precision: The inter-day precision study was performed on three different days i.e. day1, day2 and day3 at three different concentration levels, $(n=3)$. The intra-day precision study was performed on the same day at 3 intervals of time at three different concentration levels $(n=3)$. The $\%$ RSD of the inter-day precision was found to be $1.91 \%$ and intra-day precision was found to be $1.34 \%$ (Table1).

Table1: Intra-day and inter-day precision studies of Tramadol Hydrochloride

\begin{tabular}{llllll}
\hline $\begin{array}{l}\text { Sr. } \\
\text { No. }\end{array}$ & $\begin{array}{c}\text { Concentration } \\
(\mu \mathrm{g} / \mathrm{ml})\end{array}$ & Intra-day precision* & $\%$ RSD* & Inter-day precision* & $\%$ RSD* \\
\hline \multicolumn{7}{c}{} & Mean peak area \pm SD & \multicolumn{3}{c}{ Mean peak area \pm SD } \\
\hline 1 & 20 & $4724.66 \pm 94.22$ & 1.99 & $4643.66 \pm 37.03$ & 0.79 \\
\hline 2 & 30 & $7261.33 \pm 31.00$ & 0.42 & $7204.33 \pm 97.72$ & 1.35 \\
\hline 3 & 40 & $9573.66 \pm 109.52$ & 1.14 & $9895.00 \pm 20.70$ & 0.20 \\
\hline \multicolumn{7}{c}{ Mean of three replicates $(\boldsymbol{n}=3)$}
\end{tabular}

Accuracy: The accuracy of the method was evaluated triplicate at three concentration levels $(80,100$ and $120 \%)$, and the percentage recoveries were calculated.
The recovery\% in accuracy study was found to be between $98-102 \%$ and $\%$ RSD was less than $2 \%$ (Table 2).

Table 2: Accuracy-recovery study of Tramadol Hydrochloride by standard-addition method

\begin{tabular}{lllll}
\hline Sr. No. & $\begin{array}{l}\text { Amt. of } \\
\text { Sample }(\mu \mathrm{g} / \mathrm{ml})\end{array}$ & $\begin{array}{l}\text { Spiked } \\
\text { Concentration }(\mu \mathrm{g} / \mathrm{ml})\end{array}$ & Recovery* $(\%)$ & $\%$ RSD* \\
\hline 1 & 30 & $80 \%$ & $98.40 \%$ & 0.41 \\
\hline 2 & 30 & $100 \%$ & $98.19 \%$ & \\
\hline 3 & 30 & $120 \%$ & $102.04 \%$ & \\
\hline
\end{tabular}

Robustness: The robustness of method was performed by small changes in flow rate $(0.9$ and $1.1 \mathrm{ml} / \mathrm{min}$.). Robustness was studied using three replicates of concentration level at $100 \%$. The $\%$ RSD in robustness study was less than $2 \%$, his indicates that the method is precise, accurate and robust.
LOQ and LOD: The LOQ and LOD were based on the standard deviation of the response and the slope of the constructed calibration curve $(n=3)$, as described in International Conference on Harmonization guidelines Q2 (R1). The LOD was found to be $0.377 \mu \mathrm{g} / \mathrm{ml}$, and the value LOQ was found to be $1.144 \mu \mathrm{g} / \mathrm{ml}$.

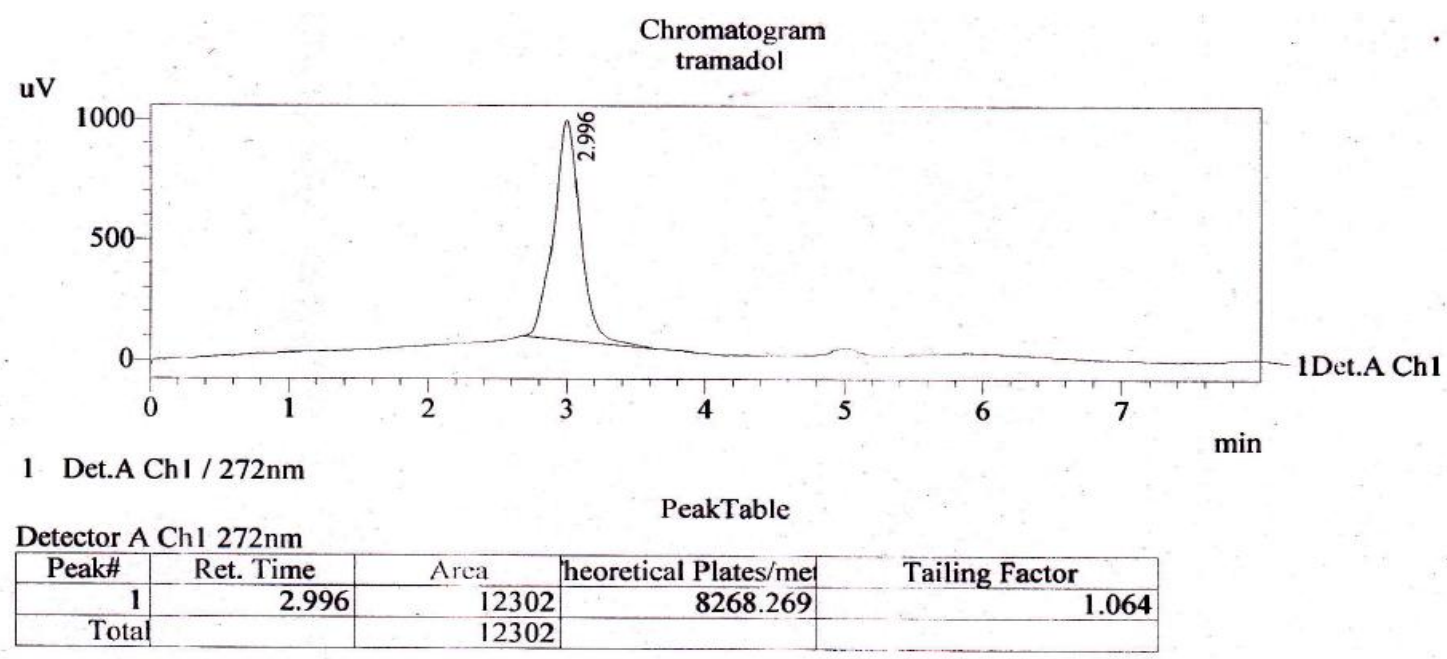

Figure 2: Chromatogram of Tramadol HCl

\section{CONCLUSION:}

The developed method was novel, simple, accurate, precise and reproducible, which would be used to estimate Tramadol $\mathrm{HCl}$ in bulk form for routine analysis. This method may also be useful for the simultaneous estimation of Tramadol $\mathrm{HCl}$ with other hydrophobic drugs. 


\section{REFERENCES:}

1. Goodman, Gilman's. The pharmacological basis of therapeutics, $10^{\text {th }}$ ed. Delhi, McGraw Hill 2001 358-360.

2. Ashutosh D. Thakur, Simultaneous estimation of tramadol hydrochloride and chlorzoxazone by absorbance correction method, J. Pharmacy Research, 2011, 4(6), 1683-1684.

3. Sawant R, Bhangale L, Joshi R and Lanke P, Validated spectrophotometric methods for simultaneous estimation of paracetamol, domperidone and tramadol hcl in pure and tablet dosage form, J. Chem. Metrol, 2010, 4(1), 21-27.

4. Setty K. N, Ramachar T, Chakravarthy I. E and Prabhavathi $\mathrm{K}$, A simple spectrophotometric estimation of tramadol hydrochloride in pharmaceutical formulations, Chem Sci Trans., 2012, 1(2), 317-320.

5. Khaggeswar. B et al, New validated uv spectrophotometric method for the estimation of rebamipide and tramadol in bulk and dosage forms, Der Pharmacia Lettre, 2011, 3(1), 298-306.

6. Rajitha B, Prashanthi S, Extractive spectrophotometric determination of tramadol hydrochloride in pure and pharmaceutical dosage forms, Int. J. Pharm. Tech Research, 2011, 3, 114-117.

7. Gharge D, Dhabale P, Simultaneous estimation of tramadol hydrochloride and paracetamol by uv spectrophotometric method from tablet formulation, Int. J. Pharm. Tech Research, 2010, 2(2), 1119-1123.

8. Gandhimathi M, Ravi T. K, Nilima S and SowmiyaG, Ind. J. Pharm. Sci., 2007, 6, 145-147.

9. Krzek J and Starek M, Biomed. Chromatogr., 2004, 18, 589599.

10. Karunakaran $\mathrm{K}$, Navaneethan $\mathrm{G}$ and Elango KP, Development and validation of a stability-indicating rp-hplc method for simultaneous determination of paracetamol, tramadol hcl and domperidone in a combined dosage form, Tropical J. Pharm Research, 2012, 11(1), 99-106.

11. Kumar S.N., Gowda D.G., Mantelingu K and RangappaK.S, Development and validation of hplc method for determination of tramadol hydrochloride in solid dosage form, J. Pharmacy Research, 2012, 5(3), 1438-1440.

12. Kamble R M, Singh S G and Singh S, Validated rp-hplc method for simultaneous estimation of paracetamol and tramadol hydrochloride in a commercial tablet, J. Pharmacy Research, 2011, 4(11), 4038-4040.

13. Prasad Y R, Rajasekhar K K, Shankarananth V, Keerthisikha P, Ravindra A and Sujitha M M, RP-HPLC method for the estimation of tramadol in bulk and capsule dosage form, J. Pharmacy Research, 2011, 4(3), 886-887.

14. Manure Md. J Y, Sayyed Md. A G, Tamboli A M, Ravetkar A S and Mohite S.K, Analytical method development of tramadol hydrochloride and chlorzoxazone in bulk and its formulation, J. Pharmacy Research, 2010, 3(9), 2296-2299.

15. The Indian Pharmacopoeia 2010, Government of India ministry of Health \& family welfare, 2010, 3, 2245-2247.

16. British Pharmacopoeia 2009, the department of health, London: The Stationary Office, 2009, 2, 6100-6104.

17. The United State Pharmacopoeia XXIV. National formulary, XX, Rockville MD: The US Pharmaceutical Convention 2007.

18. ICH guidelines, Validation of Analytical Procedures: Text and Methodology Q2 (R1), in: Proceedings of International Conference on Harmonization, 2005. 